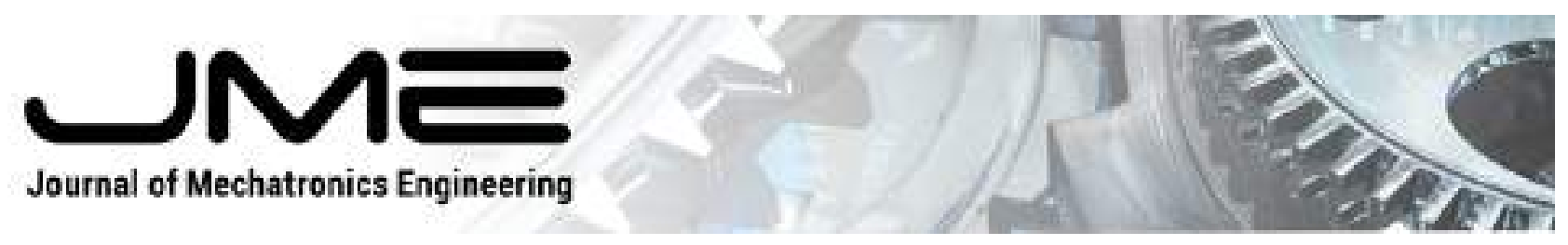

\title{
Retrofitting in Fabric Finishing Machine - Sanforizadeira
}

\author{
MAdSOn do Nascimento ARAújo $^{1}$, Josias Guimarẽes Batista ${ }^{1}$, \\ André Pimentel Moreira $^{1}$, DANiElle Alves Barbosa ${ }^{1}$ LinCONL LOBO DA Silva $^{1}$ \\ ${ }^{1}$ Federal Institute of Education, Science and Technology of Ceará - IFCE, Fortaleza, CE - Brazil - 60040-531 \\ <mdsn.araujo@gmail.com>, <josiasbatista@ifce.edu.br> \\ <apmoreira@ifce.edu.br>, <daniellealves@ifce.edu.br>, <linconllobo@gmail.com>
}

DOI: http://dx.doi.org/10.21439/jme.v4i2.98

\begin{abstract}
With the advancement of technology in all fields, mainly in the industrial sector, which is manifested in more modern and self-contained equipment. Many types of equipment in the industry are obsolete with the electrical and electronic parts, but the mechanical parts are in perfect condition and can often be used for a long time. This paper demonstrates the retrofitting of a fabric finishing machine (Sanforizadeira) in the textile process that was obsolete. In these conditions, it became necessary to retrofit the automation system. Through the study of the machine and the process, involving the fields of production and mechanical maintenance, the critical points and the improvements that should be implemented were found, thus raising the materials needed to carry out the work. The automation system was modernized, the control panels were replaced and improvements were implemented. The final result was achieved through the objectives outlined in this work, guaranteeing the company a system with considerable improvements, with a reduction in the number of stops and time spent for maintenance. The results were demonstrated by the graphs of the maintenance indicators. Comparing the before and after retrofitting, the following indicators were analyzed for six months: Failure rate, with an average reduction of 50\% in the failure rate per hour; Mean time between failures, showed an average increase of 140 hours in the prediction of the next failures; Average time to repair, presented an average reduction of thirteen minutes in the resolution of the failures; Availability, there was a $16 \%$ increase in the availability of the machine, leaving the indicator above $90 \%$ where the ideal is $100 \%$. Finally, the total cost of the project represented only $9.5 \%$ of the total value of a new machine is also considered a positive result for the work.
\end{abstract}

Keywords: Retrofitting. Sanforizing machine. Automation system. Textile process. Maintenance indicators.

\section{Introduction}

The competitiveness of the market leads industries to invest more and more in their manufacturing process, to always present a quality final product according to the standards and specifications of the customers. Seeking to serve their customers and remain effective in the market, companies turn to industrial automation, which is used in industries to streamline and accelerate production, providing a process with little human intervention and better quality in the final product. One of the disadvantages of industrial automation is the rapid modernization of equipment the trend is that deployed applications will become obsolete more quickly with the advent of new technologies.

The project presented by this work was developed in the textile industry. We can highlight that industrial automation, together with the development of robotics and the phenomenon of globalization, increased capitalist competition from the local to the global scope, supporting the transformations that took place in this sector. With globalization, the Brazilian consumer market now has access to fabrics from other nations in the world, of superior quality and with more affordable prices. This phenomenon required the replacement and modernization of machinery as impositions of the new context of the competition. Automatic machines brought new requirements for handling, controls and new demands 
Retrofitting in Fabric Finishing Machine - Sanforizadeira

(SOUZA; ANDRIOLA, 1999).

Retrofitting is idealized and planned through strategies developed by maintenance management. Maintenance can be defined as a set of actions aimed at ensuring the proper functioning of machines and installations, ensuring that they are intervened at the right opportunities and with the right reach to prevent them from falling or decreasing in performance and, in the case of such happen, that they are restored to good operational conditions as soon as possible, all at an optimized global cost (CABRAL, 2009).

In the paper from Mourtzis, Angelopoulos e Panopoulos (2020) was presented a conceptual framework to assist the decision-making process, supported by an online network and based on Augmented Reality for retrofitting and recycling machinery, aiming at increasing components' lifecycle. Al-Maeeni et al. (2020) showed a way to use augmented reality to retrofit a production machine. Augmented reality was implemented using Microsoft HoloLens. In a case study, a way was researched how to help the machine user to do the right things in the right sequence in order to save time and cost. Sometimes the sequences in a setup process are not clearly structured.

In the paper from Guerreiro et al. (2018) was proposed the concept of Smart Retrofitting regarding these challenges. As a result, the methodology proposes to take aspects of Industry 4.0 relevant to a specific process, since this could be the first step for a company to implement the concepts of Industry 4.0. Once these aspects was selected, they will was put into practice with the help of cyber-physical systems. With the application of Smart Retrofitting, it will was possible for companies to adhere in a short time to the requirements of Industry 4.0. In this way, it will was possible to remain competitive in the market.

In paper from Lins et al. (2018) was proposed, a way of performing the retrofitting process for Industry 4.0, through a platform that, regardless the model or type of the industrial equipment, offers resources to integrate this equipment with Industry 4.0. To implement the platform, requirements and technologies necessary to perform retrofitting for Industry 4.0 were defined. Afterward, the methods usage in the platform were presented.

The textile industry is composed of a long productive chain from the arrival of the raw material, cotton, to the delivery of the final product to the customer, the fabric. The retrofitting was carried out in a fabric finishing machine that takes the name of sanforizadeira, the same is inserted in the process of saforization. It is a final process in which the fabric is subjected to significant efforts and major transformations and any failure can result in the loss of a long production chain to which the fabric was subjected and, consequently, in losses (JORGE, 2007).

The industry has a continuous need to update its processes, as new technologies are constantly emerging to help optimize production. This need leads companies to seek increasingly qualified employees to analyze problems arising from the manufacturing process. In order not only to solve the punctual problems of machine stoppage, but also to analyze the origin, root cause, of the defects that generate stoppage and loss of production. Within this scenario of analysis and always taking into account the cost benefit, the need arose to carry out retrofitting. The number of interventions by the corrective maintenance team and the time the machine was stopped while it was supposed to be working to meet demand, were also key points that encouraged the elaboration of the project.

The choice of the theme arises from the author's need to perform the present work in the professional context and covers the comparison of the before and after retrofitting and analyses the results generated by the work. The work does not include gains in the production or dimension of cables and electrical panel construction materials.

This paper has as main objective to perform the retrofitting in a fabric finishing machine (Sanforizadeira), to replace the control panels and to implement the necessary improvements pointed out by the production and mechanical maintenance sector. This work can be classified as applied research because it deals with the solution of an efficiency problem applied practically in the industrial scope. and it can be classified as quantitative for performing an analysis of measurable data of maintenance indicators comparing the before and after of the project. Finally, the work can be classified as experimental, because through technical procedures the materials and methods to be used for the execution of the project were analyzed and defined.

The remainder of this paper is organized as follows. In Section 2 the theoretical basis is presented with the concept of industrial automation, an explanation of maintenance management, and the types of indicators. Section 3 presents the machine that was retrofitted and how it works in the process, the constituent materials, and the steps for preparing the work. Section 4 presents the analysis of the results obtained, through the graphics 
and calculations performed based on the maintenance indicators. Finally, in Section 5 conclusions are drawn on the researched topic and the possibilities for future work.

\section{Theoretical Foundation}

This section looks at the theoretical concepts of the most relevant subjects that underlie the elaboration of the work. Concepts and characteristics of Retrofitting, Industrial Automation and Maintenance Management.

\subsection{Retrofitting}

According to Ribeiro et al. (2007) retrofitting is the updating of equipment, technologically obsolete, through modern applications and automation devices. Retrofitting is widely used in machines and/or processes where the demand for production is increasing, both in quantitative and qualitative terms. This makes the theme recurrent in the industrial sphere since the need to stand out in the market leads companies to always seek improvements to meet their demands (FERREIRA; BENTO; MORALES, 2018). He suggests that the retrofitting of an equipment or production process also aims at its optimization, obtaining products with a reduced unit cost in a shorter time and with greater uniformity. This is achieved indirectly when the following objectives are achieved:

- Increase and control the quality of the product;

- Increase productivity;

- Increase the reliability of the process;

- Make the data related to the process available for analysis;

- Increase security about people and the environment.

The implementation of retrofitting also provides for aesthetic improvement and in many cases, it is used in companies that need to minimize maintenance losses, with simpler programming features and greater availability of spare parts for a longer time. According to Grams e Cetnarowski (2013)) retrofitting can be divided into five stages: equipment evaluation, project development, purchase of materials, project implementation, and tests.

\subsubsection{Step 1: Equipment evaluation}

Objectives are set through an initial assessment of the machine. In this evaluation, the machine is disassembled and the data of its components are collected. Through conversations with operators and maintainers, the best way to carry out the project is defined.

\subsubsection{Step 2: Project development}

Based on the original design of the equipment, another project is made containing the modifications that will be made in the revitalization of the machine.

\subsubsection{Step 3: Purchase of materials}

After the evaluation, approval of the budget, and completion of the project, purchase orders are defined for the specified materials. This step is essential for maintaining the stipulated deadline. Although the purchase time is taken into account in the schedule, any delay, whether it is an order preparation or product delivery, may influence the final delivery date.

\subsubsection{Step 4: Project implementation}

After the arrival of the materials, the project enters the execution phase. You can divide the execution of this into two parts: hardware retrofitting and software retrofitting.

\section{Hardware Retrofitting}

First, all old equipment that will no longer be used is dismantled. Then the new instruments are implemented on the machine, strictly following the electrical scheme previously developed. After implementation, the actual assembly is checked with the one specified in the project.

\section{Software Retrofitting}

If the customer has a backup of the program in process and the new controller is compatible with the old one, retrofitting the software is facilitated. Otherwise, the information acquired through the operator and the maintainer responsible for the machine is used to develop the new control software.

\subsubsection{Step 5: Tests}

As the program is developed, small tests are done to ensure that the logic is working. With the end of the program, parts start to be produced and "fine adjustments"are made. After the completion of the tests, the machine continues to be monitored for some time that varies according to the complexity of the system. 
Retrofitting in Fabric Finishing Machine - Sanforizadeira

\subsection{Industrial Automation}

Rosário (2012) suggests that automation is any process that performs tasks and activities autonomously or that assists man in his day-to-day tasks. Making a quick historical overview on the topic. Lamb (2013) adds that the term automation was created in 1940 by an engineer from the Ford Motor Company, who described several systems in which automatic actions and controls replaced human effort and intelligence.

For Lamb (2013) some of the advantages of automation are:

1. Human operators with heavy or monotonous tasks can be replaced;

2. Human operators who performed tasks in dangerous environments, such as those with extreme temperatures or radioactive and toxic atmospheres, can be replaced;

3. Tasks that are beyond human capacity have been facilitated. The handling of large or heavy loads, the handling of tiny elements or the requirements to manufacture a product very quickly or very slowly are an example of this;

4. Frequent and faster production and labor costs are lower per product compared to equivalent manual operations;

5. Automation systems are able to easily incorporate inspections and checks in order to reduce the number of products outside a certain production standard, allowing statistical process control that will generate more consistent and uniform products;

6. Automation serves as a catalyst for improving the economy of companies and society. For example, the gross national product and the standard of living in Germany and Japan increased dramatically in the 20th century, largely because these countries incorporated automation into their production of arms, automobiles, textiles, and other export goods;

7. Automation systems don't get sick.

Mikell (2011) completes there are some more common reasons to justify automation which are the following:

1. Increase productivity. The automation of production operations usually increases the rate of production and the productivity of labor;
2. Reduce labor costs. Greater investment in automation has been economically justified as a way to replace manual operations;

3. Minimize the effects of the lack of workers. There is a general decline in qualified labor in many developed countries, which encourages the development of automated operations as a way to replace workers;

4. Reduce or eliminate manual routines and administrative tasks. The automation of such tasks increases the general level of working conditions;

5. Increase worker safety. The automation of a given operation and the transfer of the worker from the active role in the process makes work safer;

6. Improve the quality of the product. Performs the production process with greater uniformity and compliance with quality specifications;

7. Shorten the production time. It helps to reduce the waiting time between the customer's order and the delivery of the product;

8. Carry out processes that cannot be performed manually. Some tasks cannot be performed without machine help.

An automated system if used with different equipment to guarantee its operation. We can highlight the CLP as one of the most important. These are microprocessor-based controllers that use instructions stored in programmable memory to implement logic, sequencing, time, counting and arithmetic control functions in order to control machines and processes (MIKELL, 2011). PLCs can be divided into three types: compact, modular and soft-PLC. As main characteristics of the PLC we can mention the use of discrete processes; application in fixed or flexible automation; he is the direct heir of the old relay boards; performs combinational logic which means producing a combination of output variables from a combination of inputs; performs sequential logic, a combination of inputs together with a combination of the previous situations of these or other variables, produce certain outputs; uses programming languages among others.

\subsection{Maintenance management}

Maintenance management is the correct management of maintenance, that is, the organization of human and 
material resources, inputs, and strategic planning necessary for machines, equipment, and installations of any company to be in good working condition and to meet production needs. existing (ALMEIDA, 2018).

Maintenance, as a strategic function of organizations is directly responsible for the availability of assets, is of paramount importance in the company's results. These results will be all the better the more effective the maintenance management (OTANI; MACHADO 2008).

Maintenance management directly grounded and determined the project. Combining the need to update the machine and the analysis of its result indicators in the manufacturing process. The strategic planning and the consolidated maintenance team guaranteed the results.

Through some maintenance indicators, the results of retrofitting were analyzed and compared with the results prior to the realization of the project. (XAVIER 1998 ) adds that Indicators serve to tell us where we are and allow us to define where we want to go.

The indicators used in the work performed were: failure rate, mean time between failures (MTBF), mean time to repairs (MTR), and availability.

\subsubsection{Failure rate $(\lambda)$}

Measures the frequency of failure occurrence. The failure rate is defined from the total number of failures that occurred in a given time of operation, according to Equation (1).

$$
\lambda=\frac{\text { Total number of failures }}{\text { Operating time }}
$$

\subsubsection{Mean time between failures (MTBF)}

It is defined as the mathematical expectation of the time between failures of an item (ABNT, 1994). According to Equation (2), it can be obtained in the relation between the time of operation and the number of failures or the inverse of the failure rate.

$$
M T B F=\frac{1}{\lambda}=\frac{\text { Operating time }}{\text { Number of failures }}
$$

\subsubsection{Mean time to repair (MTR)}

MTR demonstrates the ability to repair certain equipment. As can be seen in Equation (3), it is obtained between the sum of the repair times and the number of interventions.

$$
M T R=\frac{\sum(\text { Operating time })}{\text { Number of interventions }}
$$

\subsubsection{Availability (A)}

Expresses the ability of an item to be able to perform a certain function at a given time or for a specified period of time (ABNT, 1994). Equation (4) can be obtained between the relationship between MTBF and MTR.

$$
A=\frac{M T B F}{M T B F+M T R}
$$

\section{Methodology}

In this section, the steps for preparing the retrofitting are described, in addition to containing a description of the main materials used in the project and an explanation of the operation of the machine where the work was carried out.

\subsection{Contextualization}

As previously mentioned, the project was carried out in a textile industry more precisely in the sanforization process. The fabric improvement and finishing sector are responsible for this process. The sector has a large number of variables that must be controlled to guarantee quality and meet product specification limits. The place where the process is inserted is characterized by noise and heat resulting from the operation of the machines, in addition to cotton residues resulting from the process.

\subsection{Main materials used}

\subsubsection{PLC}

The PLC used in the project was a modular type that has modules coupled through a rack and controlled by the CPU, a module that contains programmable memory.

\subsubsection{PLC input and output modules}

The PLC modules are connected by a rack that guarantees communication between them. The modules are used to input and output information necessary for the functionality of the process or machine they control. For each type of information, there is a specific module or card responsible for transmitting the data. In the case of the presented project, 3 digital input cards, 2 digital output cards, 1 analog input, and 1 master module were 
used for data transmission on the Profibus DP network. All modules were connected by a 16-position rack.

\subsubsection{Frequency converter}

The frequency converter is electronic equipment that, through a supply frequency, makes a variation of it capable of providing control and speed variation in electric induction motors. This type of control provides a series of advantages, such as smoother acceleration starts and greater precision in the movements of the motors. For this reason, the frequency converter is of fundamental importance for the project, since the speed of the machine is determined by the control of several engines running in series and the accuracy of this speed is decisive for the final quality of the product. The frequency converter of the manufacturer Schneider Electric $($, model ALTIVAR 312 was used in retrofitting. Figure 1 contains examples of frequency converters used in the project.

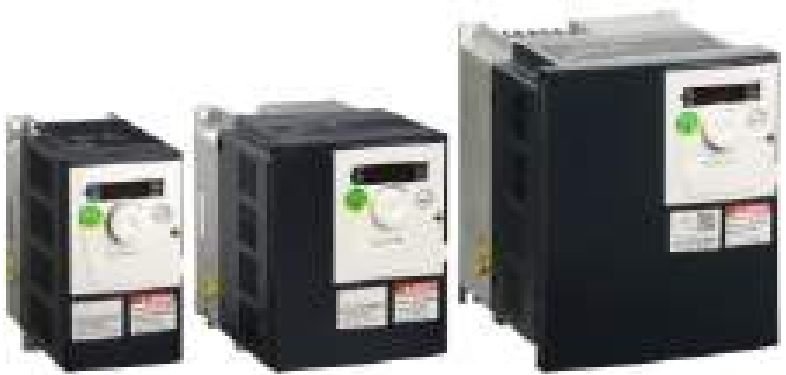

Figure 1: Frequency converter (Schneider Electric $®)$.

\subsubsection{Potentiometer}

The potentiometer is a three-terminal resistor where the central connection is sliding and manipulable. If all three terminals are used, it acts as a voltage divider. At work, the potentiometer was used to measure the distance between two cylinders. Figure 2 shows an example of the potentiometer used at work.

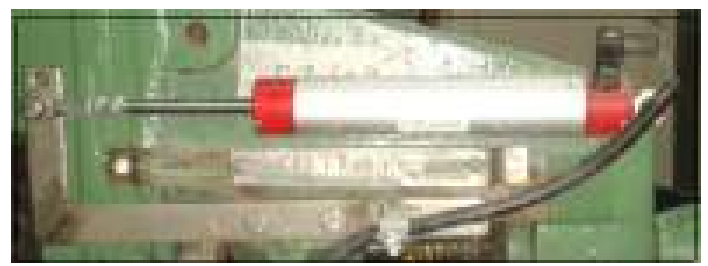

Figure 2: Potentiometer.

\subsection{Steps and stages of the project}

The steps for preparing retrofitting will be described below.

\subsubsection{Step 1 - Study of Retrofitting}

In Step 1 of the work, the preliminary procedures for the implementation of the project were carried out, a study of the machine and its operation were carried out, the need to implement improvements was analyzed together with the sectors of mechanical maintenance and production, and finally, a survey was carried of the materials needed to start retrofitting.

The machine has been analyzed in parts to facilitate its understanding and operation, its main function is to apply a pre-shrinkage to the fabrics so that there is no significant shrinkage in the first washing of customers. Figure 3 shows the general view of a sanforizadora inserted in the industrial processor.

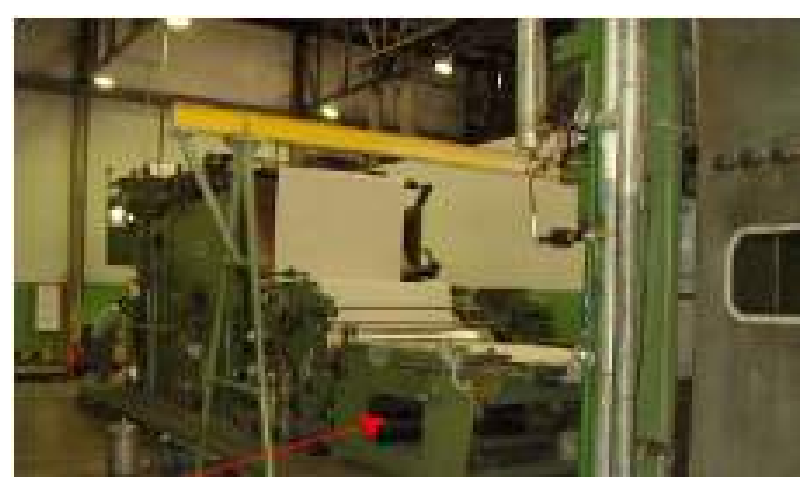

Figure 3: General view of a sanforizadora.

Next, Figure 4 shows a schematic diagram of the sanforizadora containing all the components usually used in the machine.

1: Tissue entry;

2: Water jet - the moisture of the fabric influences the final shrinkage;

3: Vaporizer drum together with the unit (2) controls the moisture of the fabric;

4: Weft straightener;

5: Rama 1.2 or $2.4 \mathrm{~m}$ with tweezers - ensures the stretch of the fabric;

6: Shrinkage unit with rubber stain;

7: Felt calender (Palmer) - fixes the shrinkage;

8: Drum to dry the felt;

9: Output of the fabric in diaper. 


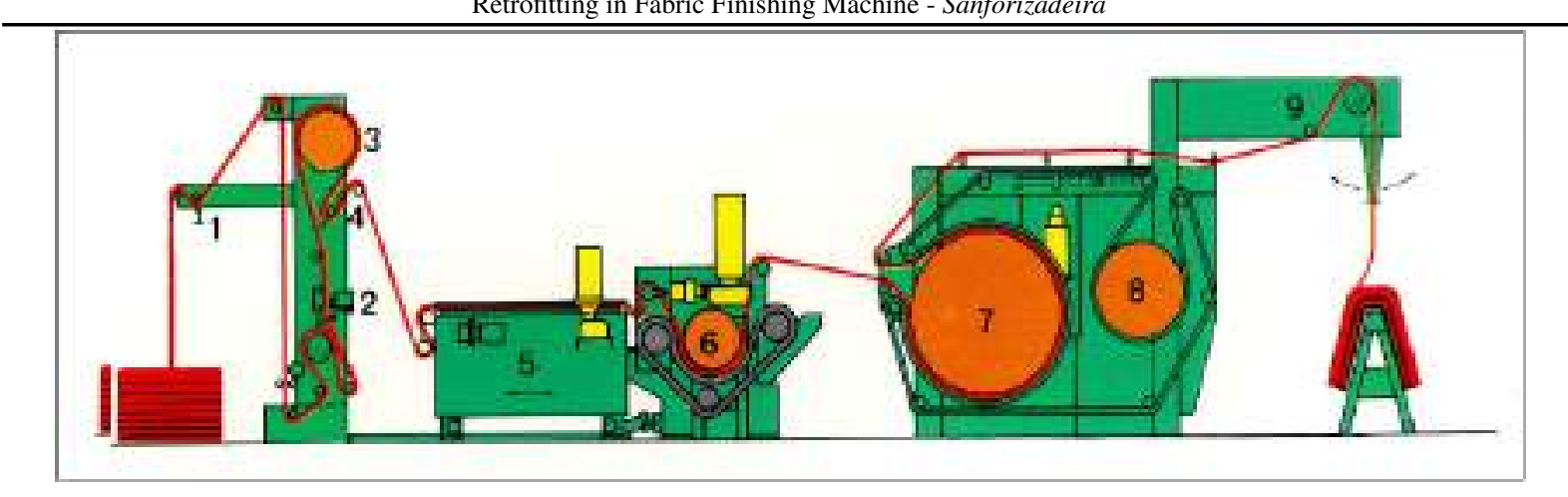

Figure 4: General view of a sanforizadora.

\subsubsection{Step 2 - Improvements}

At this stage, the implementation of improvements was also discussed. The mechanical maintenance sector suggested a change in the pressure control of the stain, as it is an expensive part and with the control that was being used on the machine, this part had a reduced useful life. . What happened was that in order to reach the required shrinkage value for the part that was running on the machine, the production applied excessive pressure to the pad not respecting the manufacturer's specifications. The compression of the patch could not exceed $30 \%$ of its nominal thickness. Before this pressure was limited by inductive sensors that functioned as a limit switch and were not very precise in controlling the thickness. Any error when adjusting the distance from the sensors resulted in the misuse of this equipment. It was then suggested to implement the control of the thickness of the patch by a linear potentiometer, a more precise control that had already been used in another unit of the company.

\subsubsection{Step 3 - Tests}

In this stage, all the necessary tests were carried out to adjust the machine and make it ready for production. Initially, all controls were tested individually, starting with the traction motors, which were tested and adjusted separately. In this test, the tangential speed of each motor was synchronized, so that the part that passes through the machine remains with uniform speed throughout. After the engines were synchronized, the temperature controls of the machine's cylinders were tested. Finally, a test piece was inserted and the production sector took over the operation of the machine, a way to test every machine without risk of losing raw material. After all the tests carried out and the produc- tion sector's approval, the machine went into operation and started to produce again.

\subsubsection{Step 4 - Analysis of the results obtained}

In this stage, the final surveys of the project were carried out, going through the calculations of the results obtained and the costs necessary for the elaboration of the retrofitting. According to the formulas in subsection 2.4 "Maintenance Management", calculations were made to obtain the maintenance indicators of the old system that had already registered its maintenance performances. The new system was analyzed for 6 months, at which time the data collected for the formulation of the indicators for comparison with the old system.

\section{Results}

This section presents the results obtained in the retrofitting of the sanfonizadeira machine.

\subsection{Results of machine improvement}

Analysis of the machine was extremely favorable due to the authors' knowledge of the production process and where it fits.

The construction of the panels followed the entire project elaborated, wherein this step the equipment was also fixed and the control connections of the panel were made. This step took place within the expected time. Figure 5 demonstrates the panel before and after retrofitting. Figure 6 shows the fixing of the frequency converters before and after retrofitting. Figure 7 shows a comparison of the PLC fixation before and after retrofitting. 
Retrofitting in Fabric Finishing Machine - Sanforizadeira

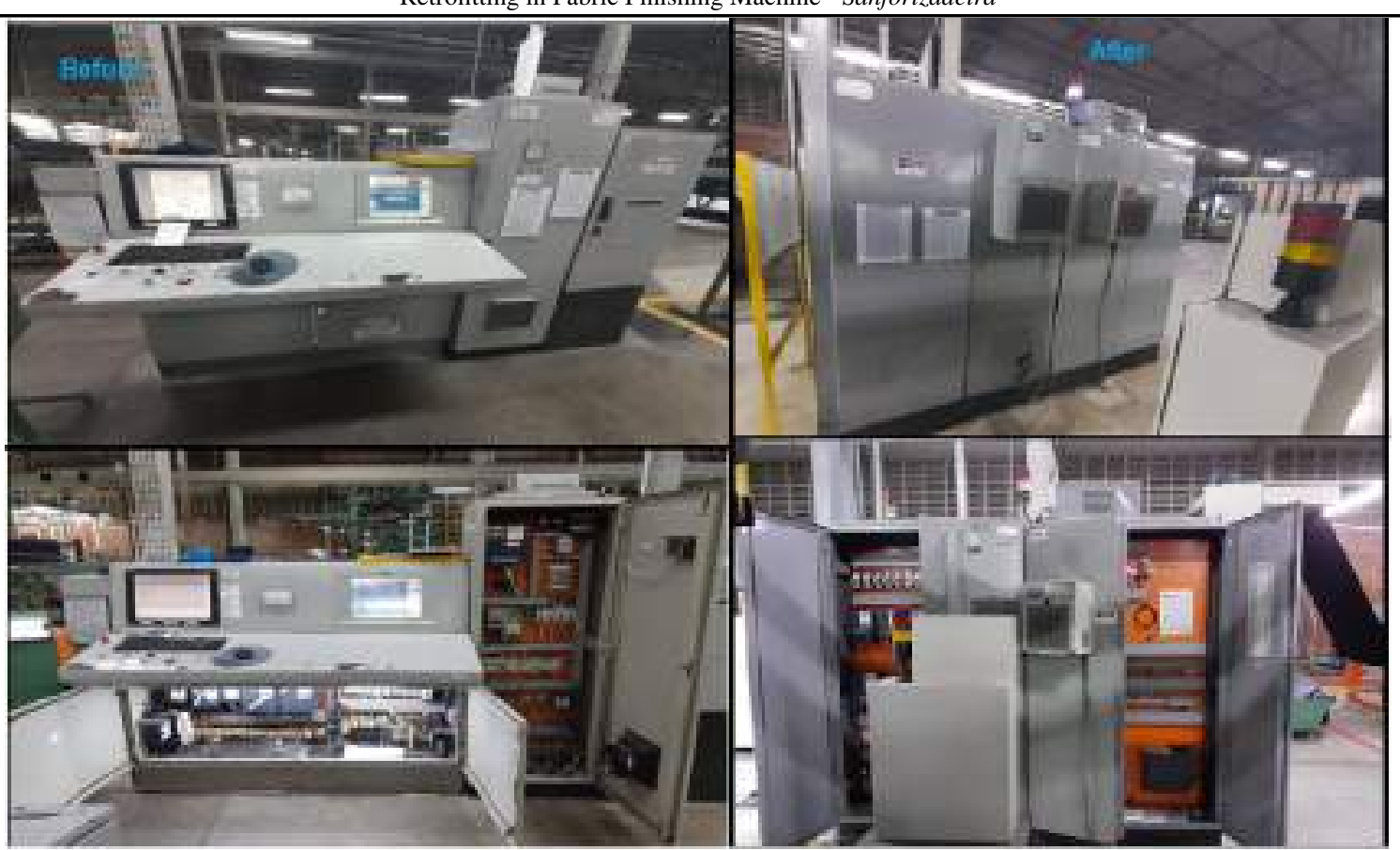

Figure 5: Panel before and after retrofitting.

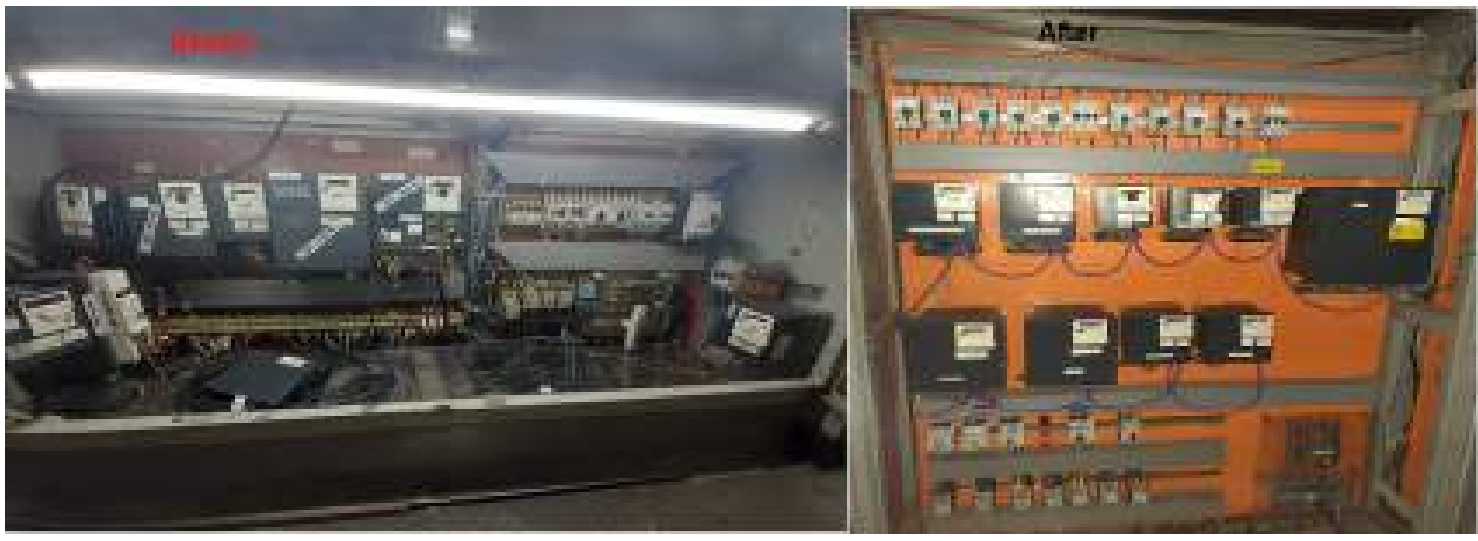

Figure 6: Fixing frequency converters before and after retrofitting.

\subsection{Results of maintenance indicators}

After the analysis of the system and possession of the collected data, graphs with maintenance indicators were elaborated, comparing the system before and after retrofitting. The first indicator addressed was the failure rate, which, with a 4320 hour operating time, showed a positive result, with a $50 \%$ drop in the failure rate per hour, calculating the average of the two years, the only divergence was the first month. where there were some specific defects in the adaptation period, as shown in
Figure 8

The second indicator to be calculated was the MTBF, which also showed a positive result compared to the old system, increasing the average time between failures by about 140 hours, as shown in Figure 9 .

The third indicator analyzed was the MTR, for the values that correspond before the retrofitting, we observed a drop in the repair time caused by strategic measures to solve defects generated by failures in the PLC entry and exit cards, as the PLC is no longer manufac- 

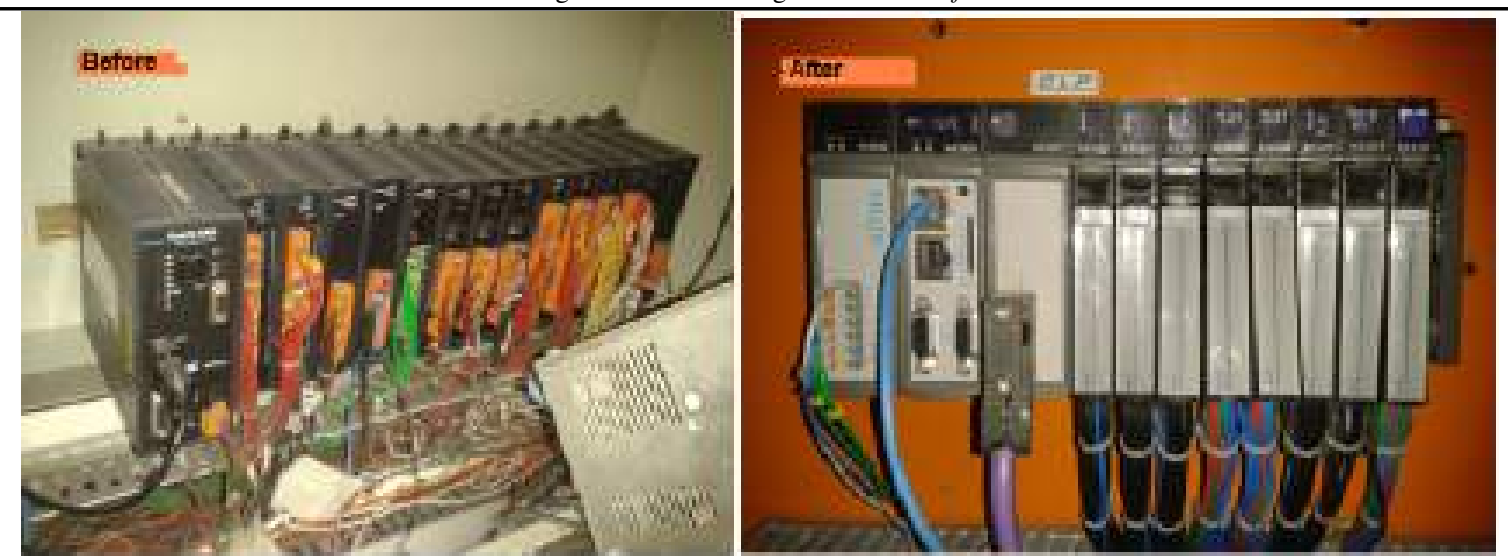

Figure 7: Fixing the PLC before and after retrofitting.

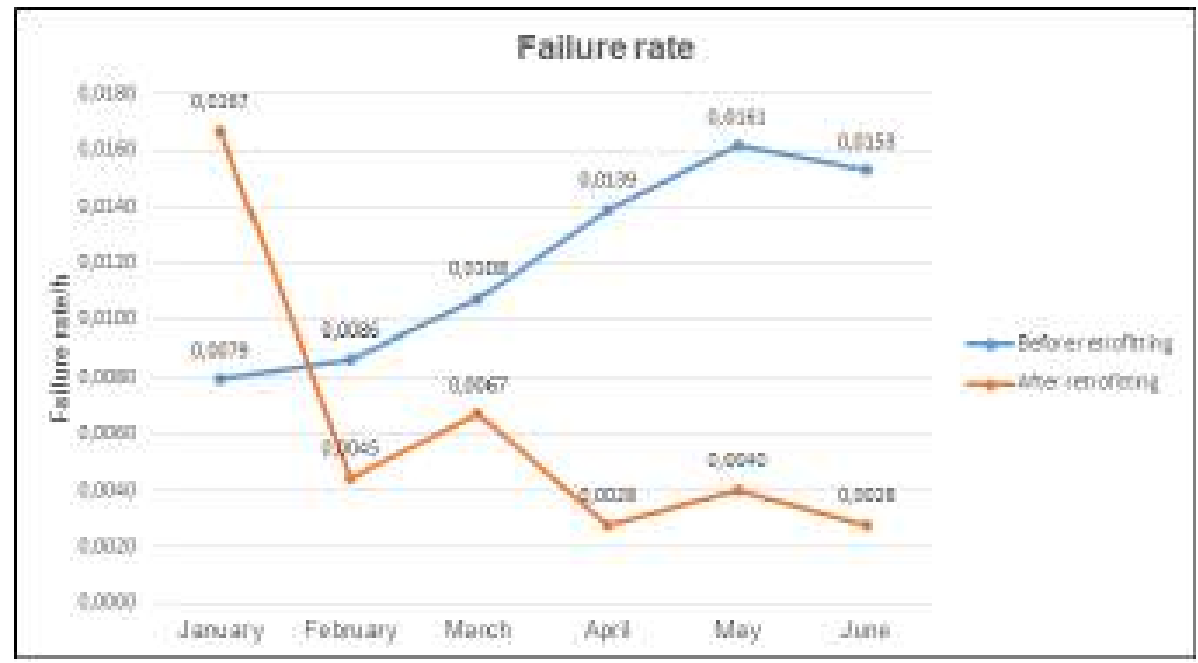

Figure 8: Failure rate graph

tured. the punctual measure was to remove the part and carry out repairs in the electronic maintenance sector, some digital input and output cards were located and transferred from other units of the company, thus reducing the MTR of the same year. The results were favorable, where on average there was a reduction of thirteen minutes in attending to the failure, as shown in Figure 10

The fourth indicator analyzed was the availability of the implemented system. The results were also favorable, where although in February the system before retrofitting presented a better result, on average, the new system showed an average increase of $16 \%$ in the availability of the machine as shown in Figure 11 .

\subsection{Discussions}

Despite the difficulty, all tests were performed as expected. The production sector tested the entire machine for three days before the machine started to produce effectively again. During the production tests, special attention from the electrical maintenance sector was needed to resolve any doubts or problems that might arise. The biggest doubts were about the automatic pressure control of the pad that was inserted.

The machine maintenance data were collected in the first six months after retrofitting, with the data in hand, the indicators were calculated and graphs were drawn up to compare the performance of the machine with the same period of the year prior to the project. It was proven through the graphics that after retrofitting the 


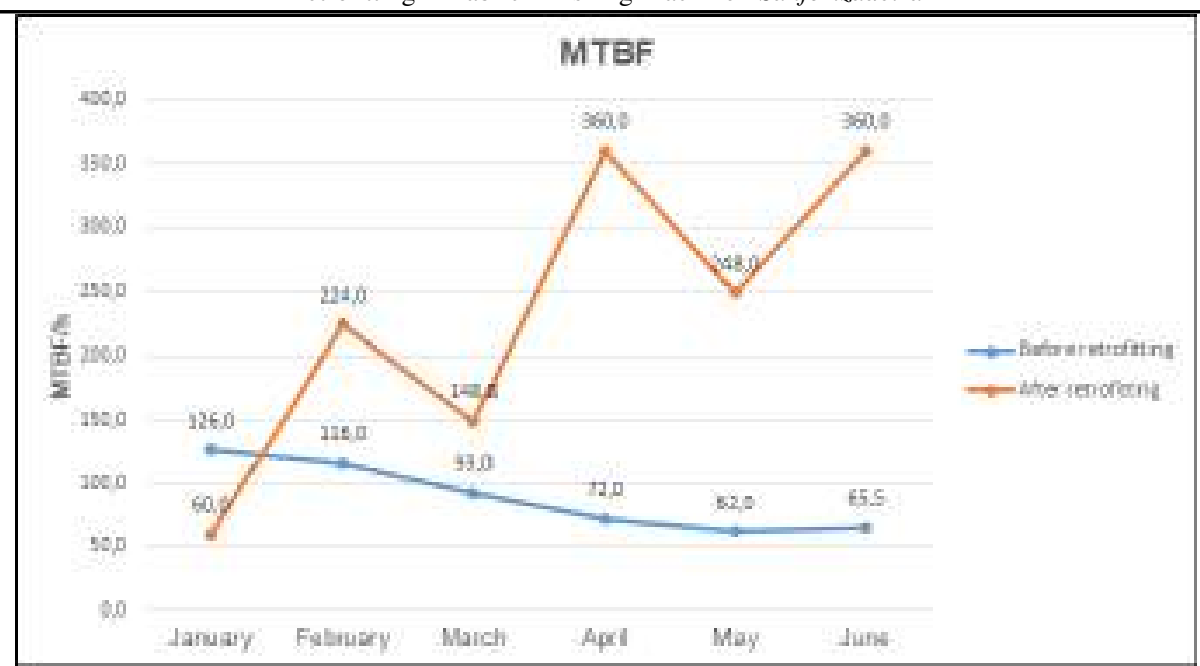

Figure 9: MTBF graph.

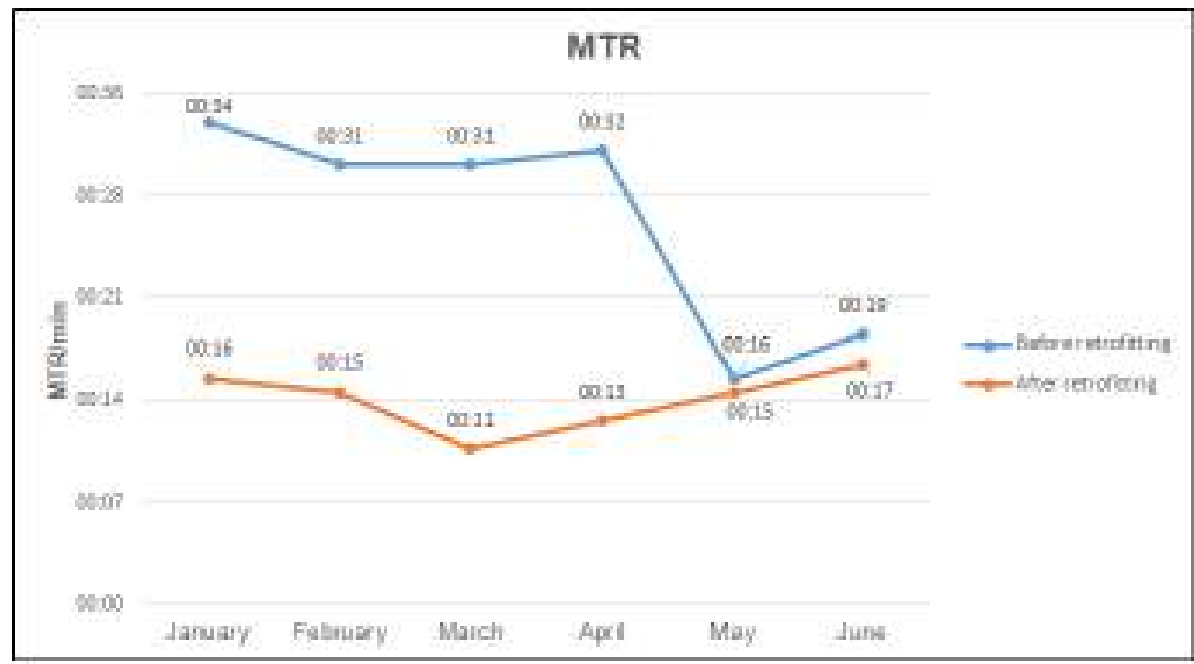

Figure 10: MTR graph.

machine improved its maintenance indicators, ensuring better performance.

The costs were within expectations, as the amount invested in the project costs about $9.5 \%$ of the total value of a new machine, which is $205,569.75$ US dollars.

\section{Conclusions}

This work addressed the implementation of retrofitting combined with industrial automation, promoting the modernization of the studied application and seeking the best possible solution. The solution presented was the implementation of retrofitting.
The general objectives of performing the retrofitting in a fabric finishing machine (Sanforizadeira), replacing the control panels, and implementing the necessary improvements pointed out by the production and mechanical maintenance sector, were fully achieved, providing significant improvements in the maintenance indicators pointed out by the work. The indicators analyzed were failure rate, MTBF, MTR, and availability.

For the execution of the work, a list of all the materials that would be needed for retrofitting was made. The layout for the control panels was prepared. The PLC program was elaborated, a Profibus DP network 


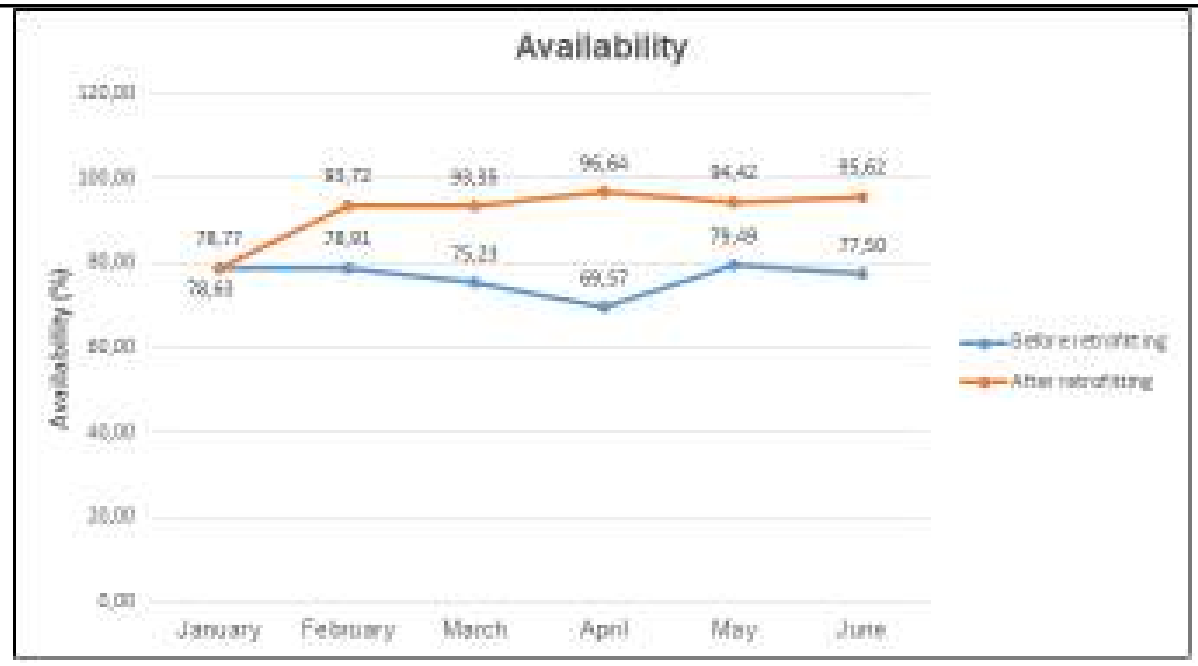

Figure 11: Availability graph.

was implemented in the communication of the inverters and for the communication of the supervisor, it was necessary to change the communication protocol. Finally, the machine's PLC was included in the company's intranet network, facilitating its monitoring.

The work presented some limitations related to the time to carry out the work because when all the necessary elements for the performance of the retrofitting were gathered, the machine could only be stopped for one month for the implementation of the work, the collective vacation period of the company.

It can also be concluded that this work brings a contribution to the area as it presents the steps for the implementation of a retrofitting of automation equipment used in the textile industry.

As future work, it is suggested to monitor the production rates for better monitoring of the system, through the production rates we can check the quality of the fabric and the quantity of low quality caused by a defect in the machine. Another suggestion is to take advantage of the connection to the ethernet network and generate a bank with the main parameters of the machine, in this way we can analyze any drop in quality and observe if any operational method is no longer carried out and contributed to the low quality of the final product.

\section{References}

ABNT, N. 5462. confiabilidade e mantenabilidade. Rio de Janeiro, p. 6, 1994.
AL-MAEENI, S. S. H.; KUHNHEN, C.; ENGEL, B.; SCHILLER, M. Smart retrofitting of machine tools in the context of industry 4.0. Procedia CIRP, Elsevier, v. 88, p. 369-374, 2020.

\section{ALMEIDA, P. S. de. Gestão da Manutenção Aplicado às Áreas Industrial, Predial e Elétrica. [S.1.]: Saraiva Educação SA, 2018.}

CABRAL, J. P. S. Gestão da manutenção de equipamentos, instalações e edifícios. Biblioteca Industria \& Serviços, LIDEL, April, 2009.

FERREIRA, J. H. G.; BENTO, L. F.; MORALES, I. M. Aplicação de retrofit em sistema de comando e controle de um chiller. Revista Científica Semana Acadêmica. Fortaleza, ano MMXVIII, n. 000147, 2018.

GRAMS, C. A.; CETNAROWSKI, E. Retrofit em máquinas industriais: estudo de caso. Dissertação (B.S. thesis) - Universidade Tecnológica Federal do Paraná, 2013.

GUERREIRO, B. V.; LINS, R. G.; SUN, J.; SCHMITT, R. Definition of smart retrofitting: First steps for a company to deploy aspects of industry 4.0. In: Advances in Manufacturing. [S.1.]: Springer, 2018. p. $161-170$.

JORGE, D. C. T. Tecnologia de medição não invasiva do encolhimento e homogeneidade de cores em processos têxteis. Universidade Federal de Minas Gerais, 2007. 
LAMB, F. Industrial automation: hands-on. [S.1.]:

McGraw-Hill Education, 2013.

LINS, T.; OLIVEIRA, R. A. R.; CORREIA, L. H.;

SILVA, J. S. Industry 4.0 retrofitting. In: IEEE. 2018

VIII Brazilian Symposium on Computing Systems

Engineering (SBESC). [S.1.], 2018. p. 8-15.

MIKELL, P. Automação industrial e sistemas de manufatura. [S.1.]: Pearson Brasil, 2011.

MOURTZIS, D.; ANGELOPOULOS, J.;

PANOPOULOS, N. Recycling and retrofitting for industrial equipment based on augmented reality. Procedia CIRP, Elsevier, v. 90, p. 606-610, 2020.

OTANI, M.; MACHADO, W. V. A proposta de desenvolvimento de gestão da manutenção industrial na busca da excelência ou classe mundial. Revista Gestão Industrial, v. 4, n. 2, p. 1-16, 2008.

RIBEIRO, A.; ALMEIDA, A.; SOUZA, M.; LIMA, E. Metodologia para implementação de retroffiting de controladores de equipamentos de automação de processos. In: Anais do $8^{\circ}$ Congresso Ibero-americano de Engenharia Mecânica, Cusco, Peru. [S.1.: s.n.], 2007. v. 8.

ROSÁRIO, J. M. Automação industrial. [S.1.]: Editora Baraúna, 2012.

SOUZA, W. J. de; ANDRIOLA, I. R. F. O homem e a máquina: Um estudo das imagens e representações da automação no setor industrial têxtil. ENCONTRO NACIONAL DOS PROGRAMAS DE PÓS-GRADUAÇÃO EM ADMINISTRAÇÃO, v. 23, 1999.

XAVIER, J. N. Manutenção classe mundial. In: Congresso Brasileiro de Manutenção, Salvador. [S.1.: s.n.], 1998. v. 9, n. 08. 